\title{
The dnaA gene region of Mycobacterium avium and the autonomous replication activities of its $5^{\prime}$ and $3^{\prime}$ flanking regions
}

\author{
Murty V. V. S. Madiraju, Ming-Hui Qin, Kohji Yamamoto, \\ Mark A. L. Atkinson and Malini Rajagopalan
}

Author for correspondence: Murty V. V. S. Madiraju. Tel: +1 903877 2877. Fax: +1 9038775969. e-mail: murty@uthct.edu

Department of Biochemistry, 11937 US Highway at 271, The University of Texas Health Center at Tyler, Tyler, TX 75708-3154, USA

\begin{abstract}
A 3.9 kb DNA fragment containing the dnaA gene region of Mycobacterium avium was cloned and its nucleotide sequence was determined. Nucleotide sequence analyses indicated that this region encodes three genes in the order rpmH (ribosomal protein L34), dnaA (the putative initiator protein) and dnaN (the $\beta$ subunit of DNA polymerase III). The intergenic regions between the rpmH-dnaA and dnaA-dnaN genes were found to contain several putative DnaA boxes, 9 nt long DnaA protein recognition sequences. A DNA fragment containing the $3^{\prime}$ but not the $5^{\prime}$ flanking region of the $M$. avium dnaA gene when cloned in Escherichia coli plasmids, which are otherwise non-replicative in mycobacteria, exhibited autonomous replication activity in $M$. avium but not in Mycobacterium bovis BCG and Mycobacterium smegmatis. The 5' flanking region of $d n a A$, on the other hand, exhibited autonomous replication activity in $M$. bovis BCG but not in $M$. avium and $M$. smegmatis. The implications of these results for the understanding of the $M$. avium oriC replication initiation process are discussed.
\end{abstract}

Keywords: dnaA, oriC, Mycobacterium avium, replication initiation

\section{INTRODUCTION}

Organisms of the Mycobacterium avium-intracellulare (MAC) complex are the most common cause of nontuberculous mycobacterial infections outside the lung. Together they represent the single most common bacterial opportunistic infectious agent in AIDS, being diagnosed in up to $40 \%$ of AIDS patients. Furthermore, a recent report indicated that $M$. avium infection augments HIV-1 viral production (Wahl et al., 1998). $M$. avium is a slow-growing mycobacterium with a typical generation time ranging from 10 to $12 \mathrm{~h}$. Other mycobacteria exhibit varied growth rates with doubling times ranging from 2 to $3 \mathrm{~h}$, e.g. Mycobacterium smegmatis and Mycobacterium fortuitum; to 22 to $24 \mathrm{~h}$, e.g. members of the Mycobacterium tuberculosis complex (Wheeler \& Ratledge, 1994).

The currently accepted model is that replication in eubacteria is initiated when the DnaA initiator protein

Abbreviations: $\mathrm{Km}$, kanamycin; OAD, oleic acid-albumin-dextrose. The GenBank accession number for the sequence reported in this paper is U19185. binds to DnaA boxes ( $9 \mathrm{nt}$ DnaA protein recognition sequences) located in the origin of replication (oriC; Bramhill \& Kornberg, 1988). The nucleotide sequence of these DnaA boxes is conserved and TTGTCCACA has been defined as their consensus sequence in Grampositive bacteria with a high G $+\mathrm{C}$ content (see, for example, Fujita et al., 1990; Qin et al., 1997; Rajagopalan et al., 1995b). The DnaA protein-box interactions result in a cascade of events, which culminate in replication initiation and DNA synthesis (Bramhill \& Kornberg, 1988; Kornberg \& Baker, 1991). The $d n a A$ region in eubacteria, including M. smegmatis, M. tuberculosis and Mycobacterium leprae, shows both sequence and gene order conservation. The genes are present in the order 5'-rrnpA-rpmH-dnaA-dnaN-recF-3' (Cole et al., 1998; Qin et al., 1999; Rajagopalan et al., 1995a, b; Salazar et al., 1996). In addition it has been shown in many bacteria that either the $3^{\prime}, 5^{\prime}$ or both $3^{\prime}$ and $5^{\prime}$ flanking regions of the $d n a A$ gene exhibit oriC activity, i.e. the presence of these sequences renders otherwise non-replicative plasmids capable of autonomous replication. In the case of Bacillus subtilis both the $5^{\prime}$ and $3^{\prime}$ flanking regions act as oriC (Moriya et al., 1992). In Pseudomonas putida and Pseudomonas 
Table 1. Description of plasmids used in the study

\begin{tabular}{|c|c|c|}
\hline Plasmid & Description & Source \\
\hline \multicolumn{3}{|c|}{ Vectors used for sequencing } \\
\hline pUC18 & E. coli plasmid vector; $\mathrm{Ap}^{\mathrm{r}}$ & Lab stock \\
\hline pMQ421 & $\begin{array}{l}7 \mathrm{~kb} \text { BamHI fragment derived from the } M . \text { avium cosmid } \\
\text { containing the } r p m H \text { and } d n a A \text { regions; } \text { Ap }^{r}\end{array}$ & This study \\
\hline pMQ422 & $\begin{array}{l}\text { Same as pMQ421 except that the } 7 \mathrm{~kb} B a m H I \text { fragment } \\
\text { was cloned in the opposite orientation; } \mathrm{Ap}^{\mathrm{r}}\end{array}$ & This study \\
\hline pMQ423 & $\begin{array}{l}2 \cdot 1 \mathrm{~kb} \text { EcoRI fragment derived from the } M . \text { avium cosmid } \\
\text { containing } d n a A \text { and } d n a N \text { genes; } \mathrm{Ap}^{\mathrm{r}}\end{array}$ & This study \\
\hline pMQ431 & $1.7 \mathrm{~kb}$ SmaI-EcoRI fragment derived from pMQ421; Ap ${ }^{\mathrm{r}}$ & This study \\
\hline pMQ432.6 & $1.3 \mathrm{~kb}$ SmaI fragment derived from $\mathrm{pMQ} 434 ; \mathrm{Ap}^{\mathrm{r}}$ & This study \\
\hline pMQ432.8 & $\begin{array}{l}1 \cdot 0 \mathrm{~kb} S m a \mathrm{I} \text { fragment derived from } \mathrm{pMQ} 434 \text { (contains } \\
r p m H) ; \mathrm{Ap}^{\mathrm{r}}\end{array}$ & This study \\
\hline pMQ433 & $2 \cdot 2 \mathrm{~kb} \mathrm{KpnI-BamHI}$ fragment derived from pMQ421; Ap ${ }^{r}$ & This study \\
\hline pMQ434 & $\begin{array}{l}3 \mathrm{~kb} \text { Pst I-BamHI fragment derived from pMQ421, lacks } \\
\text { the } 5^{\prime} \text { flanking region of } r p m H ; \mathrm{Ap}^{\mathrm{r}}\end{array}$ & This study \\
\hline pMQ435 & $1 \cdot 0 \mathrm{~kb} \mathrm{BamHI} \mathrm{large} \mathrm{fragment} \mathrm{derived} \mathrm{from} \mathrm{pMQ} 423 ; \mathrm{Ap}^{\mathrm{r}}$ & This study \\
\hline pMQ436 & $2 \mathrm{~kb}$ PstI-EcoRI derived from pMQ421; Ap ${ }^{\mathrm{r}}$ & This study \\
\hline pMQ437 & $0.7 \mathrm{~kb} S m a \mathrm{I}-K p n \mathrm{I}$ derived from $\mathrm{pMQ} 434 ; \mathrm{Ap}^{\mathrm{r}}$ & This study \\
\hline pMQ438 & $5 \mathrm{~kb}$ EcoRI fragment derived from pMQ422; $\mathrm{Ap}^{\mathrm{r}}$ & This study \\
\hline pMQ439 & $\begin{array}{l}3.9 \mathrm{~kb} P s t \mathrm{I}-E c o \mathrm{RI} \text { fragment containing entire } d n a A \text { region } \\
\text { of } M \text {. avium, i.e. } r p m H, d n a A \text { and } d n a N \text { genes and their } \\
\text { intergenic regions; } \mathrm{Ap}^{\mathrm{r}}\end{array}$ & This study \\
\hline \multicolumn{3}{|c|}{ Vectors used for oriC activity } \\
\hline pMQ456 & $\begin{array}{l}1.3 \mathrm{~kb} \text { aph gene was cloned into the PstI site of pMQ423; } \\
\mathrm{Ap}^{\mathrm{r}}, \mathrm{Km}^{\mathrm{r}}\end{array}$ & This study \\
\hline pMQ457 & $\begin{array}{l}1.3 \mathrm{~kb} \text { aph gene was cloned into the PstI site of pMQ434; } \\
\mathrm{Ap}^{\mathrm{r}}, \mathrm{Km}^{\mathrm{r}}\end{array}$ & This study \\
\hline pMQ459 & $\begin{array}{l}1.3 \mathrm{~kb} \text { aph gene was cloned into the BamHI site of } \\
\text { pMQ438; } \mathrm{Ap}^{\mathrm{r}}, \mathrm{Km}^{\mathrm{r}}\end{array}$ & This study \\
\hline pMV206 & E. coli-mycobacteria shuttle vector & Stover et al. (1991) \\
\hline \multicolumn{3}{|c|}{ Vector used for DnaA overproduction } \\
\hline pKYM5 & $\begin{array}{l}1.5 \mathrm{~kb} M . \text { avium dnaA gene cloned into the NdeI/BamHI } \\
\text { sites of pET15b;Ap }\end{array}$ & This study \\
\hline
\end{tabular}

*Ap, ampicillin; Km, kanamycin.

aeruginosa only the $5^{\prime}$ flanking region acts as oriC (Yee \& Smith, 1990) while in Streptomyces spp. (ZakrzewskaCzerwinksa \& Schrempf, 1992), M. smegmatis (Qin et al., 1997; Rajagopalan et al., 1995b; Salazar et al., 1996), M. bovis and M. tuberculosis (Qin et al., 1999) only the 3' flanking region functions as oriC. The genetic elements responsible for the replication process in $M$. avium, specifically how it is initiated and regulated, are not known. In view of the clinical significance of this organism it is important to identify and characterize the key players involved in $M$. avium replication initiation. In this study we have cloned and determined the gene order of the $d n a A$ region of $M$. avium and examined whether the $d n a A$ gene flanking regions exhibit ori $C$ activity in M. avium (Rajagopalan et al., 1995b). We show that the gene order of the $d n a A$ region of $M$. avium is similar to that reported for other bacteria, and the $3^{\prime}$ but not the $5^{\prime}$ flanking region of $\operatorname{dna} A$, when cloned in non-replicative plasmids, exhibited oriC activity in $M$. avium. Interestingly the $5^{\prime}$ flanking region of $M$. avium also exhibited autonomous replication activity but only in M. bovis BCG. The implications of these results for understanding $M$. avium replication are discussed.

\section{METHODS}

Bacterial strains and growth media. M. avium MAC104 was obtained from Dr Luiz Bermudez, Kuzell Institute, San Francisco, USA; M. intracellulare $\mathrm{mc}^{2} 76$ was from Dr Raul Barletta, University of Nebraska, Lincoln, USA (FoleyThomas et al., 1995); M. smegmatis $\mathrm{mc}^{2} 155$ was from Dr W. R. Jacobs, Jr, Albert Einstein College of Medicine, Bronx, New York, USA (Snapper et al., 1990); M. bovis BCG was from Dr Y. Taniguchi, University of Occupational and Environmental Health, Kitakyushu, Japan (Goto et al., 1991); 
Escherichia coli BL21(DE3) lysogen was from Dr Studier, Brookhaven National Laboratory, New York, USA (Studier et al., 1990); and E. coli DH5 $\alpha$ was a laboratory stock. E. coli was grown in Luria-Bertani (LB) medium whereas mycobacteria were grown in Middlebrook $7 \mathrm{H} 9$ medium supplemented with oleic acid-albumin-dextrose (OAD) as described by Jacobs et al. (1991) and Rajagopalan et al. (1995b). E. coli transformants were selected on LB agar containing either ampicillin or kanamycin $(\mathrm{Km})$ at a final concentration of $50 \mu \mathrm{g}$ $\mathrm{ml}^{-1}$. Mycobacterial transformants were selected on Middlebrook 7H10 agar medium supplemented with OAD and $\mathrm{Km}$ at a final concentration of $25 \mu \mathrm{g} \mathrm{ml}^{-1}$ (Qin et al., 1997; Rajagopalan et al., 1995b).

Recombinant DNA techniques. The pYUB18-derived $M$. avium cosmid libraries were obtained from Drs Lisa Pascopella and Raul Barletta. All plasmids, unless otherwise stated, were derived from pUC18 and are described in Table 1. For selecting recombinants/transformants in mycobacteria, a $1.3 \mathrm{~kb}$ DNA fragment containing the aph gene for $\mathrm{Km}$ resistance was cloned into the multiple cloning site (Rajagopalan et al., 1995b). Plasmid DNA from mycobacterial transformants was recovered into E. coli using the zirconiabased bead-beating technique (Qin et al., 1997; Madiraju et al., 1999). Oligonucleotides used in the study were synthesized in a Pharmacia Gene Assembler Special (Pharmacia) or were purchased from Operon Technologies. Standard molecular biology techniques such as plasmid analyses, labelling of DNA and Southern hybridization techniques were as described by Sambrook et al. (1989). DNA sequencing was performed either in a Pharmacia ALF DNA sequencer using the Pharmacia autocycle sequencing kit and protocol or in a LICOR DNA sequencer at McConnel Research Laboratories, San Diego, USA. Both forward and reverse sequencing primers were used as needed to determine the nucleotide sequence of both DNA strands.

Transformation conditions. Exponentially growing cultures of M. avium (approximate $\mathrm{OD}_{600}$ of 0.5 ; Shimadzu UV-visible UV-1201 spectrophotometer, $1 \mathrm{~cm}$ path length) were diluted 100 -fold in Middlebrook $7 \mathrm{H} 9$ broth supplemented with OAD in tissue culture flasks. Cultures were incubated at $37^{\circ} \mathrm{C}$ for $8-10 \mathrm{~d}$ until they reached an $\mathrm{OD}_{600}$ of $0 \cdot 5$. One day prior to harvesting the culture, $15 \%(\mathrm{w} / \mathrm{v})$ glycine stock was added to give a final concentration of $1.5 \%$. The cultures were harvested, washed twice at room temperature with an equal volume of $10 \%(\mathrm{v} / \mathrm{v})$ glycerol, then resuspended in approximately $0 \cdot 01$ vols of the starting culture and used immediately for electrotransformation with the test plasmids. Electroporation was carried out at room temperature at $2.5 \mathrm{kV}, 25 \mu \mathrm{F}$ and $1000 \Omega$. Approximately $0 \cdot 2-0 \cdot 3 \mu$ g plasmid DNA was used in the transformation experiments. Following electroporation, $0.9 \mathrm{ml}$ Middlebrook $7 \mathrm{H} 9$ broth supplemented with OAD was added, cultures were incubated overnight at $37^{\circ} \mathrm{C}$, appropriate dilutions were spread on antibiotic plates and incubated at $37^{\circ} \mathrm{C}$ for $2-3$ weeks. The transformation efficiency with $M$. avium MAC104 under current experimental conditions was in the range of $10^{2}-10^{3}$ transformants ( $\mu$ g input plasmid DNA) ${ }^{-1}$ and was relatively poor compared to other mycobacterial strains (see Results and Discussion). The use of greater amounts of plasmid DNA ( $\sim 1 \mu \mathrm{g}$ and more), or increasing the temperature of electroporation to $37^{\circ} \mathrm{C}$ (Wards \& Collins, 1996), or the addition of D-norleucine and $m$-fluoro-D-Lphenylalanine prior to harvesting cultures (D. L. Lakey, C.
Hager, D. S. Kernodel \& K. M. Edwards, unpublished data) did not result in any increase in the transformation efficiency.

Transformation conditions for M. smegmatis, M. bovis BCG and M. tuberculosis were as described by Qin et al. (1999, 1997) and Wards \& Collins (1996). Since the oriC regions of $M$. bovis BCG and $M$. tuberculosis differ by only one nucleotide and oriC plasmids from each function in the other, the mechanism of replication initiation in M. tuberculosis and M. bovis BCG is believed to be very similar (Qin et al., 1999). Consequently, to avoid any potential risk to the experimenters all transformation experiments involving $M$. tuberculosis oriC plasmids were carried out in M. bovis BCG.

oriC activity. oriC activity was defined as the ability of $d n a A$ region fragments from $M$. avium to render E. coli plasmids, which were otherwise unable to replicate, capable of autonomous replication in $M$. avium. The results are expressed as the total number of $\mathrm{Km}^{\mathrm{r}}$ transformants obtained ( $\mu \mathrm{g}$ input DNA) ${ }^{-1}$ (Qin et al., 1997; Rajagopalan et al., 1995b). Since our results showed that the $5^{\prime}$ and $3^{\prime}$ flanking regions of the $M$. avium dnaA gene exhibited different host-specific autonomous replication activities, to distinguish between these we refer to autonomous replication activity of $M$. avium plasmids in $M$. avium hosts as ori $\mathrm{C}$ activity and replication in other mycobacterial hosts as autonomous replication activity.

Cloning of the $d n a A$ region. All plasmid manipulations were carried out in E. coli (Sambrook et al., 1989). MVM37, an oligonucleotide primer specific to the $M$. avium $d n a A$ gene $\left(5^{\prime}\right.$ AACAAGACCCGCATCGACCGGTCGCTGGCCGAG-3'; Rajagopalan et al., 1995a) was used to screen M. avium cosmid DNA libraries by colony hybridization (Sambrook et al., 1989). The cosmids from the positive clones were confirmed by Southern hybridization, probing individually with DNA fragments specific to the $r p m H$, dnaA and $d n a N$ genes. Based on these data pUC18-based plasmids with inserts containing the $3.0 \mathrm{~kb} r p m H$ and $d n a A$ genes (pMQ434) and $2 \cdot 1 \mathrm{~kb} d n a A$ and $d n a \mathrm{~N}$ genes (pMQ423) and various subclones were constructed and used to determine the nucleotide sequence of both strands of the inserts (see Fig. 1). Typically 400-500 bases of sequence per sample were obtained with the Pharmacia ALF DNA sequencer and approximately 750-1150 bases of sequence with the LICOR machine. Nucleotide sequence data were analysed by DNA Strider 1.3 and Gene Jockey programs. Once the nucleotide sequence was confirmed, the $d n a A$ region fragments in both pMQ434 and pMQ423 were joined to produce a $3.9 \mathrm{~kb}$ DNA fragment containing the $r p m H, d n a A$ and $d n a N$ genes and their intergenic regions.

Construction of plasmids overexpressing M. avium dnaA. The $M$. avium dnaA coding region was amplified by PCR using the primers 5'-CGCCTGCAGCATATGGCCGATGACCCCGGTTC-3' and 5'-CGCGGATCCCTAGCGCTTGGAGCG-3', and cloned into the NdeI/BamHI sites of the pET15b vector (Novagen). The resultant vector, designated pKYM5 and containing the M. avium dnaA gene under T7 transcription and translational signals, was introduced into $E$. coli BL21(DE3) (Studier et al., 1990). To detect the M. avium DnaA protein, E. coli cultures containing the plasmids were grown in LB broth to an $\mathrm{OD}_{600}$ of 0.8 and DnaA overproduction was then induced by the addition of IPTG for $3 \mathrm{~h}$. Cultures were harvested, both soluble and insoluble extracts were prepared (Sambrook et al., 1989), and proteins were resolved by SDS-PAGE and visualized by Coomassie blue staining (Laemmli, 1970). 


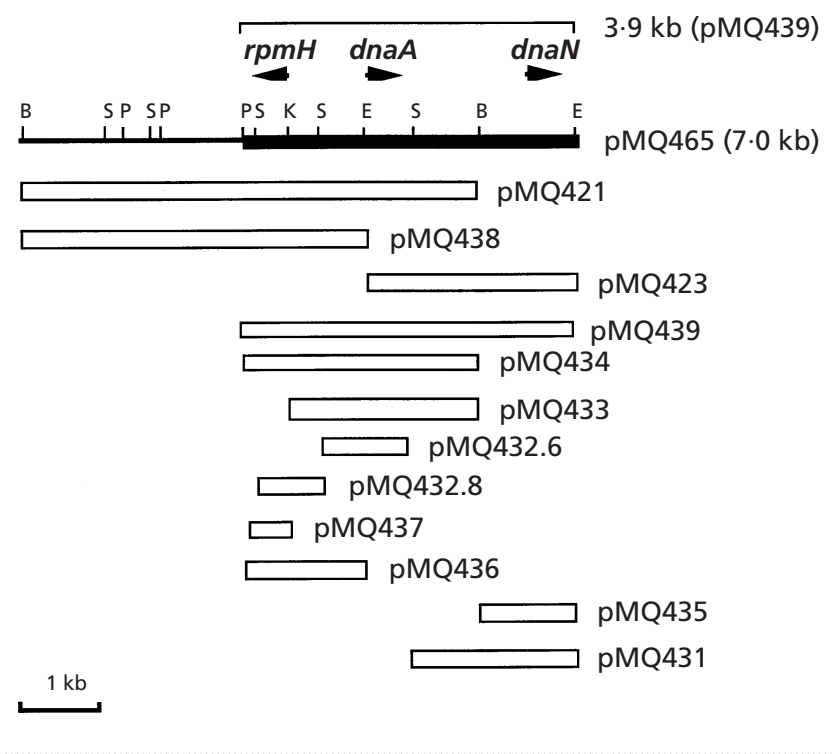

Fig. 1. The $d n a A$ region of $M$. avium. A physical map of the $7 \mathrm{~kb}$ DNA fragment containing the $M$. avium $d n a A$ gene region is shown. Single letter codes indicate restriction endonuclease sites: B, BamHI; E, EcoRl; K, Kpnl; P, Pstl; S, Smal. The $3.9 \mathrm{~kb}$ DNA fragment containing the $r p m H$, dnaA and dnaN genes is marked. The nucleotide sequence of both strands of the $3.9 \mathrm{~kb}$ DNA fragment was analysed by the DNA Strider 1.3 program to deduce the location of the $r p m H, d n a A$ and dnaN genes. Arrowheads below the genes indicate the direction of transcription. The names of the plasmid constructs used to determine the nucleotide sequence of the $d n a A$ region are shown on the right and the corresponding DNA fragments are shown on the left. Note that pMQ421 lacks dnaN whereas pMQ423 lacks $\mathrm{rpmH}$. Various subclones were derived from these plasmids (see Table 1) and were subsequently used to determine the nucleotide sequence in either the Pharmacia Automated Fluorescent DNA sequencer or the LICOR DNA sequencer.

\section{RESULTS AND DISCUSSION}

\section{The $d n a A$ region and sequence analysis}

Fig. 1 shows the various plasmid constructs used to determine the nucleotide sequence of the $3.9 \mathrm{~kb} d n a \mathrm{~A}$ region of M. avium. A BLAST search (Altschul et al., 1990) revealed homologies with the $r p m H, d n a A$ and dnaN genes of several bacteria, including M. tuberculosis and M. smegmatis (Cole et al., 1998; Qin et al., 1999; Rajagopalan et al., 1995b; Salazar et al., 1996). Three ORFs, referred to as orf1, orf2 and orf 3 , were identified. The start codons for orf1, orf 2 and orf 3 are predicted to be GTG, TTG and ATG, respectively. orf1 is smaller than orf 2 and orf3, and the direction of transcription of orf1 appears to be opposite to that of orf 2 . The putative termination codon in orf 3 was not detected.

orf1 corresponds to nucleotide positions $480-340$ of the bottom strand. It is predicted to encode an $\mathrm{RpmH}$ homologue of 47 residues with a molecular mass of $5 \cdot 3 \mathrm{kDa}$. Six nucleotides upstream of the predicted start codon, GTG, is AGAAGG, a sequence resembling that of a potential ribosome binding sequence. The predicted protein exhibits significant homology with the RpmH protein of other bacteria, including M. tuberculosis and M. smegmatis (data not shown). orf2 corresponds to nucleotide positions 1084-2610, is the largest of the three ORFs and is predicted to encode the DnaA homologue. Eight nucleotides upstream of the predicted start codon, TTG, is a potential ribosome binding sequence, AGGGAG. The predicted protein is 509 residues in length and has a molecular mass of $56.7 \mathrm{kDa}$. The deduced amino acid sequence of the M. avium dnaA gene product is 86 and $55 \%$ identical to the corresponding proteins of $M$. tuberculosis and $M$. smegmatis, respectively (data not shown). orf3 corresponds to nucleotide positions 3179-end and is predicted to encode the $d n a N$ homologue. Five nucleotides upstream of the ATG start codon is the putative ribosome binding sequence, GAAGGG. The predicted protein shows significant homology with the DnaN protein of other bacteria, including mycobacteria (data not shown).

\section{The $r p m H-d n a A$ and $d n a A-d n a N$ intergenic regions}

One of the characteristic features of eubacterial oriC is the presence of several DnaA-box-like sequences. The $r p m H-d n a A$ and $d n a A-d n a N$ intergenic regions of $M$. avium were found to contain 14 and 16 DnaA-box-like sequences with one to three mismatches to the consensus sequence TT(G/C)TCCACA, respectively (see Fig. 2; Qin et al., 1999, 1997; Rajagopalan et al., 1995b). These are clustered close to the $d_{n a A}$ gene itself with 10 of the 14 DnaA boxes in the rpmH-dnaA intergenic region located towards the $5^{\prime}$ end of $d n a A$, and 11 of the 16 DnaA boxes in the $d n a A-d n a N$ intergenic region towards its $3^{\prime}$ end. Nucleotide sequence comparisons revealed that the $M$. avium rpmH-dnaA intergenic region is 63 and $45 \%$ identical to that of the corresponding regions of $M$. tuberculosis and $M$. smegmatis, respectively, whereas the $d n a A-d n a N$ intergenic region is 62 and $50 \%$ homologous, respectively. Many of the designated DnaA boxes of $M$. avium show significant sequence homology to the corresponding position in M. tuberculosis, suggesting that the equivalent DnaA boxes in both organisms are positionally conserved (Fig. 2a and b). In contrast, the M. smegmatis sequence does not show DnaA boxes at many of these conserved positions (Fig. 2a and b). This suggests that the architectural composition of oriC of M. smegmatis differs from M. avium and M. tuberculosis (Fig. 2).

\section{Localization of oriC activity}

Plasmid constructs containing either the $r p m H-d n a A$ intergenic region (pMQ457 and pMQ459) or the dnaAdnaN intergenic region (pMQ456) were tested for their ability to exhibit oriC activity in M. avium. M. avium transformed with pMQ456 produced $\mathrm{Km}^{\mathrm{r}}$ colonies but pMQ457 and pMQ459 produced none (data not shown). The observed transformation frequency with pMQ456 was between $10^{2}$ and $10^{3}$ transformants ( $\mu \mathrm{g}$ input DNA $)^{-1}$ which is comparable to that observed with the shuttle plasmid pMV206 (data not shown). To test whether the observed $\mathrm{Km}$ resistance was due to stable 
(a)

\begin{tabular}{|c|c|c|}
\hline $\begin{array}{l}\text { Mac } \\
\text { Mtb } \\
\text { Msmeg }\end{array}$ & $\begin{array}{l}1 \\
1 \\
1\end{array}$ & 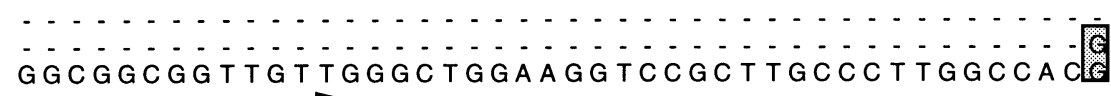 \\
\hline $\begin{array}{l}\text { Mac } \\
\text { Mtb } \\
\text { Msmeg }\end{array}$ & $\begin{array}{r}1 \\
2 \\
45\end{array}$ & GA[C G I T - C T T C C T C G \\
\hline $\begin{array}{l}\text { Mac } \\
\text { Mtb } \\
\text { Msmeg }\end{array}$ & $\begin{array}{l}32 \\
43 \\
82\end{array}$ & 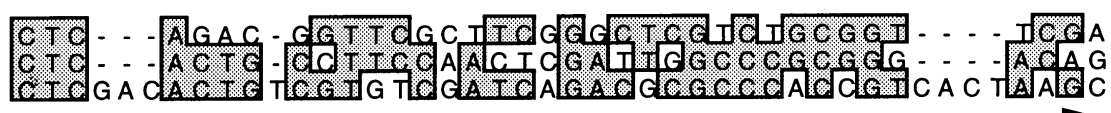 \\
\hline $\begin{array}{l}\text { Mac } \\
\text { Mtb } \\
\text { Msmeg }\end{array}$ & $\begin{array}{r}68 \\
79 \\
126\end{array}$ & 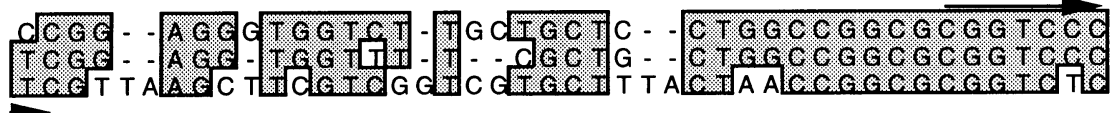 \\
\hline $\begin{array}{l}\text { Mac } \\
\text { Mtb } \\
\text { Msmeg }\end{array}$ & $\begin{array}{l}107 \\
115 \\
170\end{array}$ & 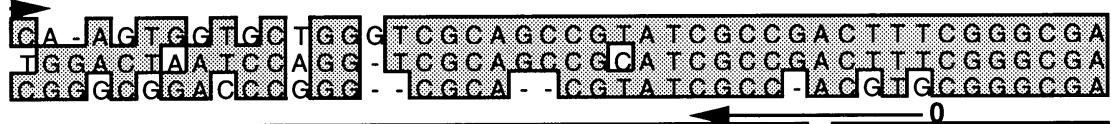 \\
\hline $\begin{array}{l}\text { Mac } \\
\text { Mtb } \\
\text { Msmeg }\end{array}$ & $\begin{array}{l}150 \\
158 \\
209\end{array}$ & 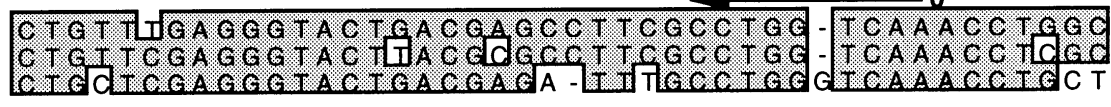 \\
\hline $\begin{array}{l}\text { Mac } \\
\text { Mtb } \\
\text { Msmeg }\end{array}$ & $\begin{array}{l}193 \\
201 \\
252\end{array}$ & 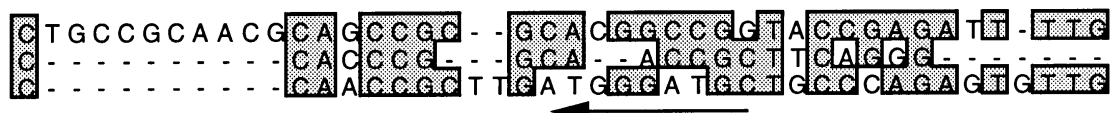 \\
\hline $\begin{array}{l}\text { Mac } \\
\text { Mtb } \\
\text { Msmeg }\end{array}$ & $\begin{array}{l}234 \\
223 \\
286\end{array}$ & 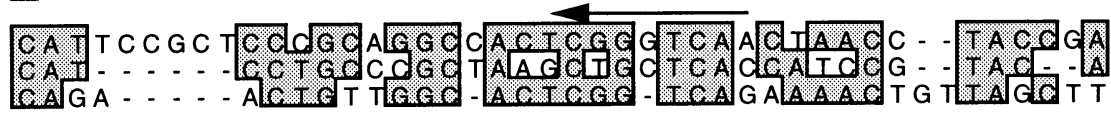 \\
\hline $\begin{array}{l}\text { Mac } \\
\text { Mtb } \\
\text { Msmeg }\end{array}$ & $\begin{array}{l}276 \\
257 \\
323\end{array}$ & 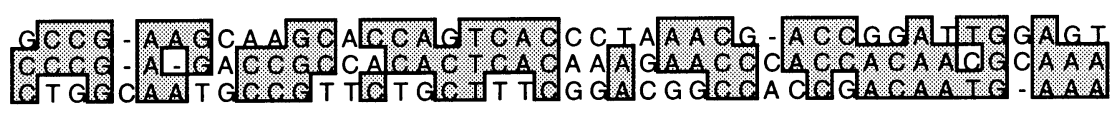 \\
\hline $\begin{array}{l}\text { Mac } \\
\text { Mtb } \\
\text { Msmeg }\end{array}$ & $\begin{array}{l}318 \\
299 \\
366\end{array}$ & 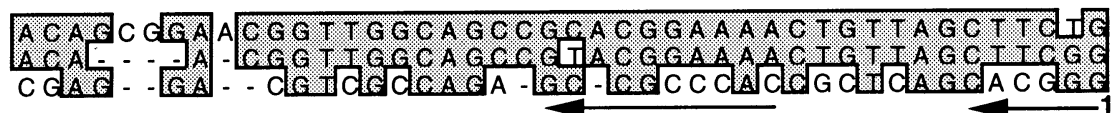 \\
\hline $\begin{array}{l}\text { Mac } \\
\text { Mtb } \\
\text { Msmeg }\end{array}$ & $\begin{array}{l}362 \\
338 \\
404\end{array}$ & 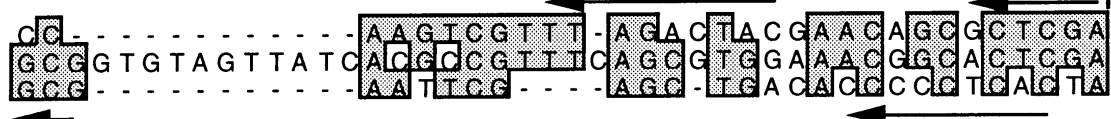 \\
\hline $\begin{array}{l}\text { Mac } \\
\text { Mtb } \\
\text { Msmeg }\end{array}$ & $\begin{array}{l}393 \\
382 \\
432\end{array}$ & 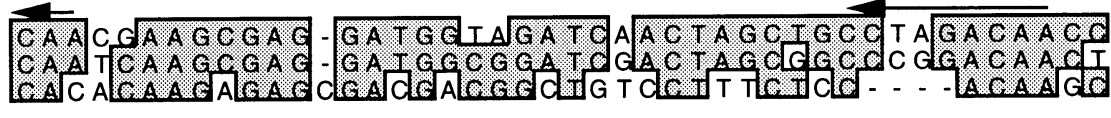 \\
\hline $\begin{array}{l}\text { Mac } \\
\text { Mtb } \\
\text { Msmeg }\end{array}$ & $\begin{array}{l}436 \\
425 \\
472\end{array}$ & 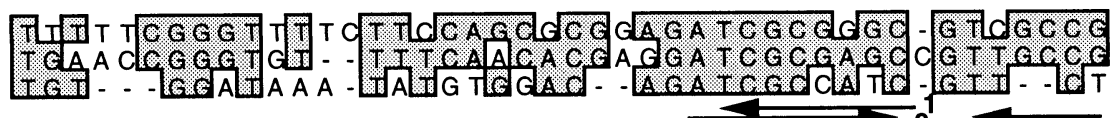 \\
\hline $\begin{array}{l}\text { Mac } \\
\text { Mtb } \\
\text { Msmeg }\end{array}$ & $\begin{array}{l}479 \\
467 \\
507\end{array}$ & 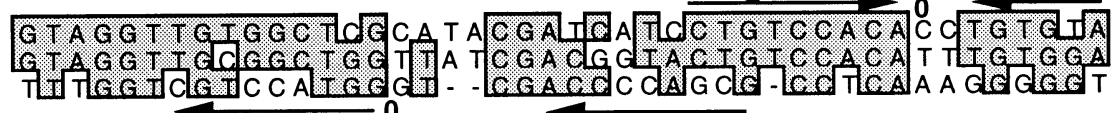 \\
\hline $\begin{array}{l}\text { Mac } \\
\text { Mtb } \\
\text { Msmeg }\end{array}$ & $\begin{array}{l}523 \\
511 \\
548\end{array}$ & 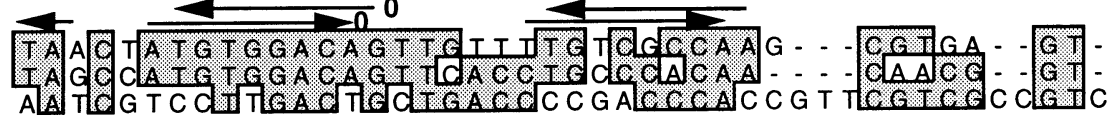 \\
\hline $\begin{array}{l}\text { Mac } \\
\text { Mtb } \\
\text { Msmeg }\end{array}$ & $\begin{array}{l}561 \\
548 \\
592\end{array}$ & 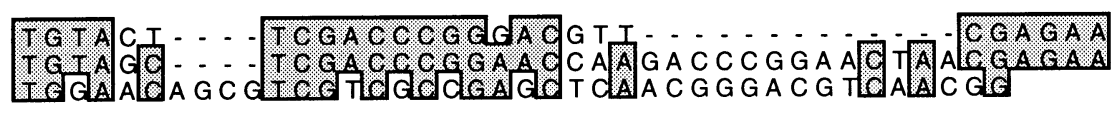 \\
\hline $\begin{array}{l}\text { Mac } \\
\text { Mtb }\end{array}$ & $\begin{array}{l}588 \\
588\end{array}$ & C - - CA G G \&A \&A TGC \\
\hline
\end{tabular}

Fig. 2. For legend see p. 2918.

extrachromosomal replication of the pMQ456, four independent transformants were streaked for single colony isolation and one independent colony from each pool was grown. Their plasmid DNA was recovered into E. coli (Qin et al., 1997) and subsequently analysed by restriction digestion. Restriction digestion patterns of the recovered plasmids were indistinguishable from that of the input plasmid used (Fig. 3), suggesting that little or no changes to the plasmids had occurred during growth and that these plasmids were indeed replicating as extrachromosomal elements in $M$. avium. The inability of the $r p m H-d n a A$ intergenic region to support oriC activity, despite the presence of multiple DnaA boxes, indicates that other factors or features are also necessary for it to exhibit oriC activity in M. avium (see below). Alternatively, this region could be involved in 
(b)

\begin{tabular}{|c|c|c|}
\hline Mac & 1 & A TCACGCCGCGGCCCCGGCCT T TCCGGCCCCCAGCCC $\mathbb{C} C A A T$ \\
\hline Mtb & 1 & $\cdots \cdots-1 \mathrm{C} A \mathrm{~A} \mathrm{C}$ \\
\hline Msmeg & 1 & $\ldots \ldots$ \\
\hline lac & 45 & 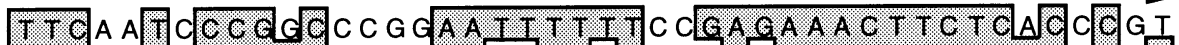 \\
\hline Mtb & 10 & 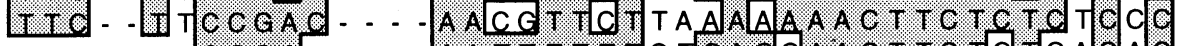 \\
\hline Msmeg & 1 & A. T T T T. T. TIG TLG.A.S \\
\hline Mac & 89 & $A C A$ \\
\hline Mtb & 48 & 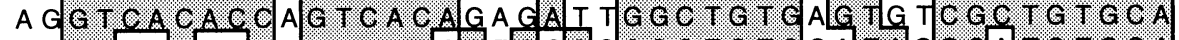 \\
\hline Msmeg & 33 & 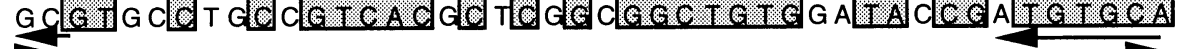 \\
\hline lac & 133 & C. A A C A O O G G \\
\hline Mtb & 92 & [C. A - $4.0,0.9$ \\
\hline Msmeg & 77 & $\sqrt{T G A D T L}$ \\
\hline Mac & 176 & 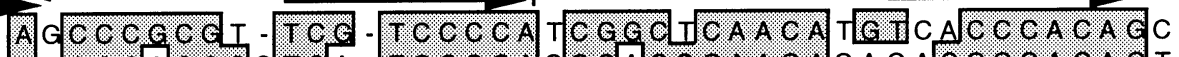 \\
\hline Mtb & 135 & 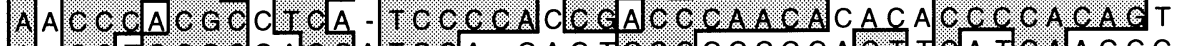 \\
\hline Msmeg & 120 & CA - C A G T G C C G G C G G A G T \\
\hline lac & 218 & 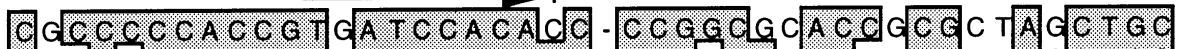 \\
\hline tb & 178 & 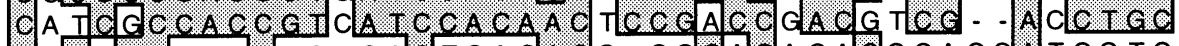 \\
\hline Msmeg & 162 & 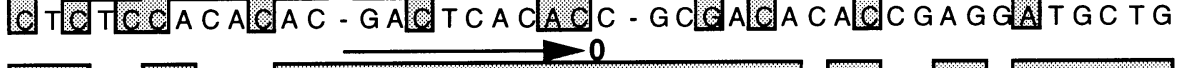 \\
\hline Mac & 261 & 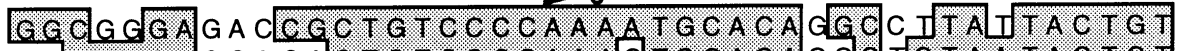 \\
\hline Mtb & 220 & 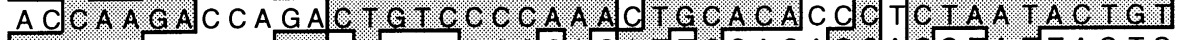 \\
\hline Msmeg & 204 & 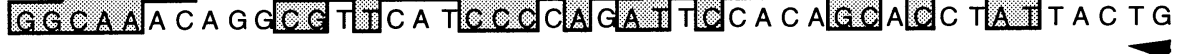 \\
\hline Mac & 305 & 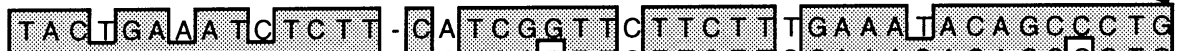 \\
\hline Mtb & 264 & TAC C GA G A T, T, T T- \\
\hline Msmeg & 248 & 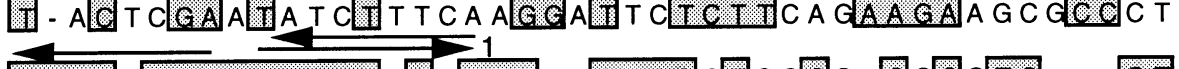 \\
\hline Mac & 348 & 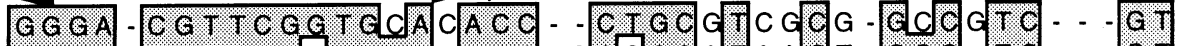 \\
\hline Mtb & 307 & 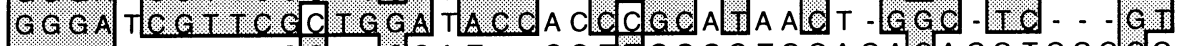 \\
\hline Msmeg & 291 & GGGA \\
\hline Mac & 385 & 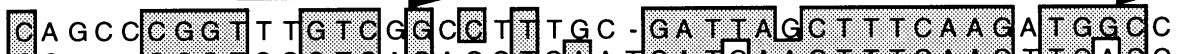 \\
\hline Mtb & 346 & 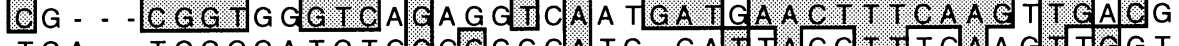 \\
\hline Msmeg & 329 & 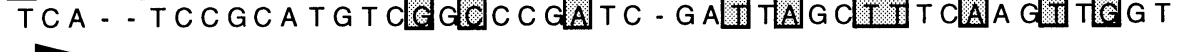 \\
\hline Mac & 428 & 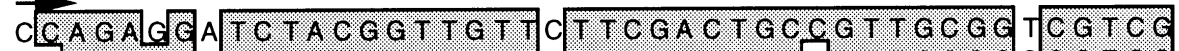 \\
\hline Mtb & 387 & 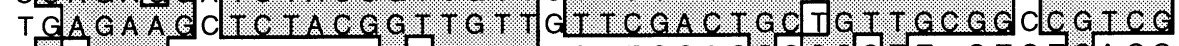 \\
\hline Msmeg & 370 & 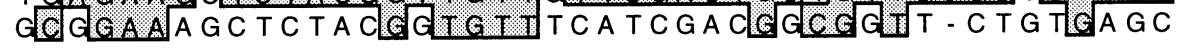 \\
\hline Mac & 472 & 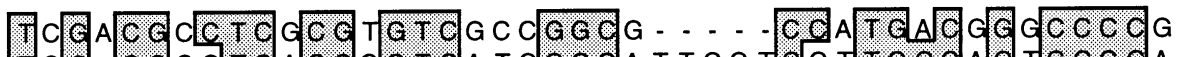 \\
\hline Mtb & 431 & 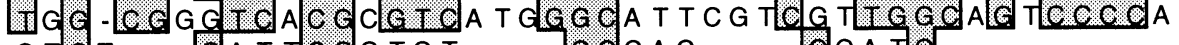 \\
\hline Msmeg & 413 & - G. OC A C - \\
\hline Mac & 511 & T $G \subset T A G \subset G G G G G A-G G \subset T A G \subset \subset A A T G G A T C C G A C A A \subset G$ G \\
\hline Mtb & 474 & 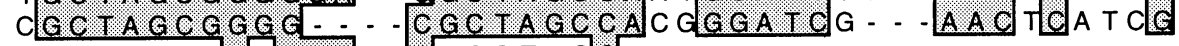 \\
\hline Msmeg & 437 & GTGCTTTCLG AGGA A CLC TGCT - GLC \\
\hline Mac & 553 & 9 T $\cdots \cdots$ \\
\hline Mtb & 511 & GA - - - - \\
\hline
\end{tabular}

Fig. 2. Nucleotide sequence comparisons of the $r p m H-d n a A$ (a) and $d n a A-d n a N$ (b) intergenic regions. Nucleotide sequence of the intergenic regions of the $r p m H-d n a A$ and $d n a A-d n a N$ of $M$. avium, $M$. tuberculosis and $M$. smegmatis were aligned using CLUSTAL W multialignment and the data are presented by using the SEQVU 1.0.1 program. Presumptive DnaA boxes of $M$. avium with one to three mismatches to the consensus sequence TTG/CTCCACA (Qin et al., 1997; Rajagopalan et al., 1995b) are shown as arrows above the sequence. The direction of the arrows indicates the orientation of the DnaA boxes. Identical nucleotide bases are shown in shaded boxes. A dash indicates a gap created for alignment. Nucleotides are numbered to the left of the sequence. DnaA boxes of $M$. avium that showed either zero or one mismatch to that of the corresponding $M$. tuberculosis sequence are marked by appropriate numbers adjacent to the arrows. Mac, M. avium 104 (U19185); Mtb, M. tuberculosis H37Rv (U38891); Msmeg, M. smegmatis mc²155 (U17833). 


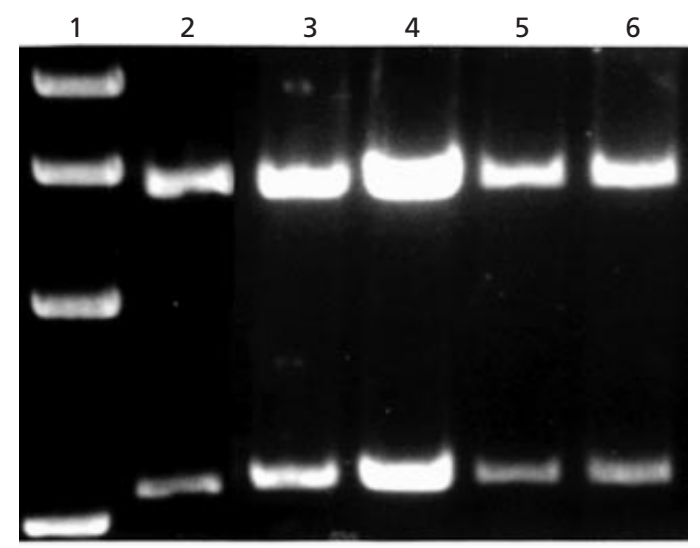

Fig. 3. Restriction digestion pattern analysis of $M$. avium oriC plasmids recovered from $\mathrm{Km}^{r}$ transformants. Four independent transformants of $M$. avium were individually propagated and plasmid DNA was recovered into $E$. coli. Plasmid DNA was purified, restricted with Pstl, electrophoretically separated in agarose gels, visualized by ethidium bromide staining and photographed. As a control, the input plasmid pMQ456 was digested with Pstl and processed as described above. Lanes: 1, $1 \mathrm{~kb}$ ladder; 2, input plasmid pMQ456 DNA digested with Pstl; 3-6, pMQ456 DNA recovered from $M$. avium transformants and digested with Pstl.

the regulation of expression of its immediate flanking genes (Atlung et al., 1987; Kornberg \& Baker, 1991; Skarstad \& Boye, 1994).

\section{M. avium oriC does not function in M. tuberculosis and $M$. smegmatis}

Replication origins from bacterial members belonging to the same family or closely related family members often appear to function in each other (Kornberg \& Baker, 1991; Skarstad \& Boye, 1994; Skovgaard \& Hansen, 1987; Smith et al., 1991; Yee \& Smith, 1990; Zakrzewska-Czerwinksa \& Schrempf, 1992; Zyskind \& Smith, 1986). These data led to the suggestion that the mechanisms involved in the initiation of replication in members belonging to the same family are similar. Mycobacteria appear to be an exception to this rule because the $M$. smegmatis oriC does not function in M. tuberculosis or M. bovis BCG and vice versa (Qin et al., 1999). To test whether the M. avium oriC functions in other mycobacteria, we electroporated M. bovis BCG and $M$. smegmatis with the $M$. avium oriC plasmid (pMQ456) and vice versa. As controls, both M. bovis BCG and M. smegmatis were also electroporated with pMV206, an E. coli-mycobacteria shuttle vector. $\mathrm{Km}^{\mathrm{r}}$ colonies were obtained only with the shuttle vector in each case and the transformation frequencies were in the range of $10^{4}$ (for $M$. bovis BCG) to $10^{5}$ (for $M$. smegmatis) transformants ( $\mu$ g input DNA $)^{-1}$. Together these data indicate that $M$. avium oriC is specific to $M$. avium. This species specificity of replication origins, despite their conserved sequence homology, suggests that the regulatory mechanisms involving the initiation of replication might be different in each of these species.

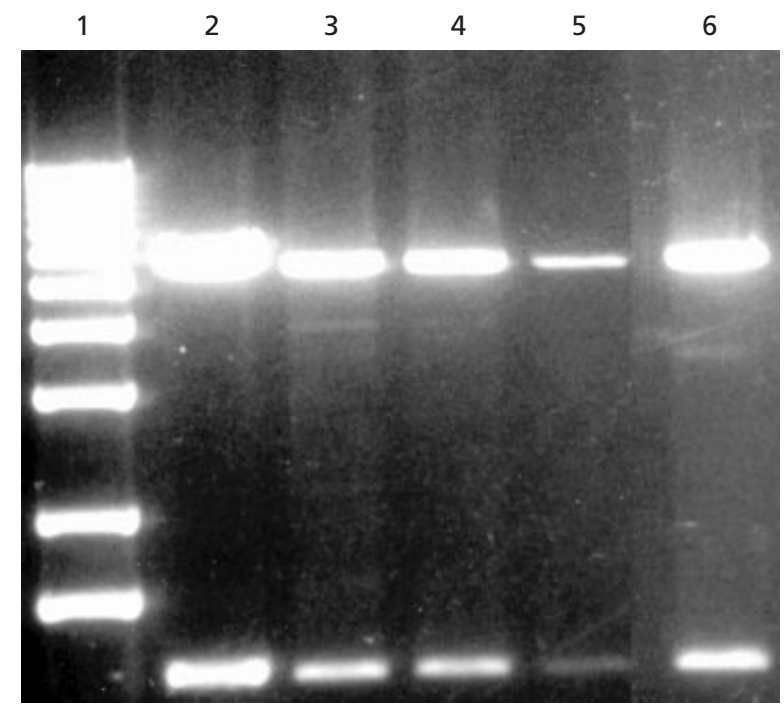

Fig. 4. Restriction digestion analysis of pMQ457 recovered from $M$. bovis BCG transformants. Four independent transformants of $M$. bovis BCG were propagated on Middlebrook 7H10 agar plates supplemented with OAD and $\mathrm{Km}$. Plasmid DNA was recovered into $E$. coli, purified, restricted with EcoRI and analysed as described in the legend to Fig. 3. Lanes: $1,1 \mathrm{~kb}$ ladder; 2-5, pMQ457 DNA recovered from $M$. bovis BCG transformants and digested with EcoRI; 6, input plasmid pMQ457 DNA digested with EcoRI.

\section{Autonomous replication activity of $M$. avium DNA fragments containing the $r p m H-d n a A$ intergenic region}

We have speculated that the $M$. avium replication origins might have evolved from B. subtilis-like organisms (Moriya et al., 1992) that selectively utilize the $d n a A-d n a N$ intergenic region as their primary oriC. If this is the case the rpmH-dnaA intergenic region may be a vestigial replication origin or alternatively it could be a silent replication origin whose activity can be unmasked under specific growth conditions, e.g. in the absence of specific inhibitors. To test this prediction, pMQ457 (containing the $r p m H-d n a A$ intergenic region) was transformed into both $M$. smegmatis and M. bovis BCG. M. bovis BCG transformed with pMQ457 produced $\mathrm{Km}^{\mathrm{r}}$ transformants but $M$. smegmatis did not (data not shown; see below). The M. bovis BCG transformants appeared 2 weeks later than those with the shuttle vector pMV206. The transformation frequency was in the range of $10^{4}$ ( $\mu$ g input DNA) ${ }^{-1}$ and was similar to that obtained with the shuttle vector pMV206. The recovered and input pMQ457 DNA showed identical restriction digestion patterns (Fig. 4), indicating that pMQ457 was replicating in M. bovis BCG as stable extrachromosomal elements (data not shown). Reciprocal experiments using M. tuberculosis, $M$. bovis BCG and M. smegmatis plasmid constructs containing their $r p m H-d n a A$ intergenic region in $M$. avium hosts did not produce any $\mathrm{Km}^{\mathrm{r}}$ transformants (data not shown). Since the transformation efficiency of M. avium strains is two to three orders of magnitude less 


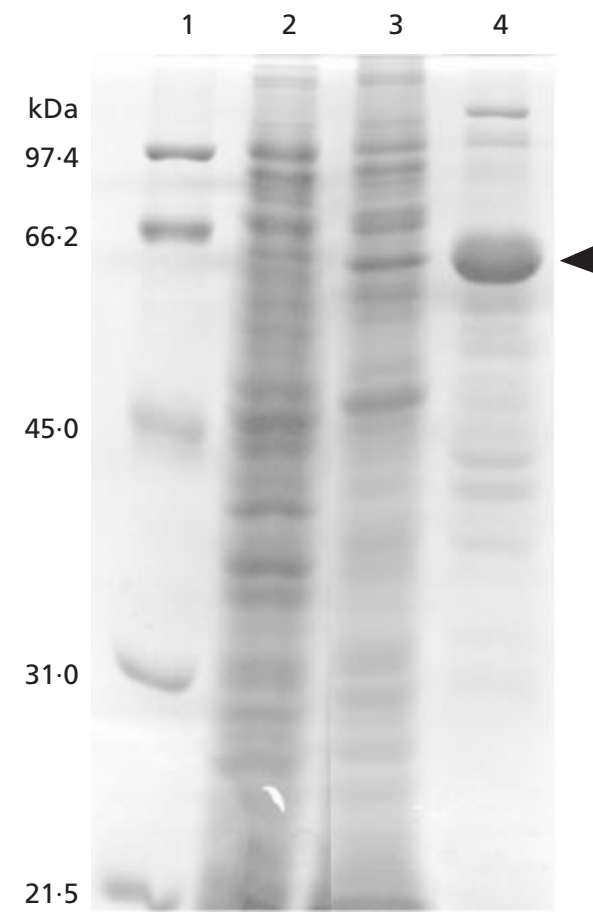

Fig. 5. Overexpression of recombinant DnaA protein. BL21(DE3) cultures harbouring pKYM5 were grown to an $\mathrm{OD}_{600}$ of 0.8 and DnaA production was induced by the addition of $1 \mathrm{mM}$ IPTG. Total lysates were prepared and centrifuged to separate the soluble and insoluble fractions. Proteins were resolved by $10 \%$ SDS-PAGE and visualized by Coomassie blue staining. Lanes: 1, protein molecular mass markers; 2, uninduced culture; 3, induced culture-soluble proteins; 4, induced cultureinsoluble proteins. The arrowhead indicates the position of DnaA.

than the other mycobacterial strains, it is possible that the lack of autonomous replication activity of those plasmids in $M$. avium may be merely due to poor transformation efficiency of $M$. avium or could be a property specific to $M$. avium. Obviously improved transformation conditions with M. avium strains would help resolve this issue.

The host-specific activities of $M$. avium DNA fragments containing the $r p m H-d n a A$ and $d n a A-d n a N$ intergenic regions we have demonstrated are distinctly different from those reported for other bacteria. The autonomous replication of pMQ457 in $M$. bovis BCG indicates that the $M$. avium rpmH-dnaA intergenic region sequence is able to utilize the $M$. bovis BCG replication machinery to initiate and replicate the pMQ457. Considering the significant sequence similarities in the intergenic region of these two organisms (Fig. 2) as well as the $d n a A$ gene itself this is not totally unexpected. However, it appears paradoxical that $\mathrm{pMQ} 457$ failed to replicate in $M$. avium. One possible explanation is that the dnaA-dnaN intergenic region of $M$. avium, which acts as a primary oriC, could exert an inhibitory effect on the oriC activity originating at the $r p m H-d n a A$ intergenic region. In this scenario the rpmH-dnaA intergenic region of $M$. avium would serve as an alternative replication origin and exhibit oriC activity in vivo only under conditions where replication at the primary oriC is inhibited or when the putative inhibitory regulators are switched off. The ability of $M$. avium to selectively utilize one or other of the replication origins might provide a selective advantage if activity from one were suppressed. This could allow it to continue to grow and divide for longer periods of time in a hostile environment.

\section{Overproduction of DnaA of $\boldsymbol{M}$. avium}

Since the interaction between the DnaA protein and DnaA boxes is believed to be the essential prerequisite for initiation of replication (Kornberg \& Baker, 1991), we have begun to investigate this process in M. avium. We have overproduced $M$. avium DnaA in E. coli. Unfortunately, most of the DnaA was in inclusion bodies (Fig. 5). We are pursuing a number of strategies to obtain soluble protein but until it can be obtained in a sufficient quantity in its native form it will not be possible to investigate its binding properties any further.

\section{ACKNOWLEDGEMENTS}

This research was supported in part by National Institutes of Health Grants AI-41406 (MM) and AI-37956 (MR). We thank Drs Luiz Bermudez and Raul Barletta for M. avium MAC104, libraries and transformation protocols, Drs W. R. Jacobs Jr and Y. Taniguchi for M. smegmatis and M. bovis BCG strains, respectively, and Dr Z. Hatahet for help in preparing the photographs.

\section{REFERENCES}

Altschul, S. F., Gish, W., Miller, W., Myers, E. W. \& Lipman, D. J. (1990). Basic local alignment search tool. J Mol Biol 215, 403-410.

Atlung, T., Lobner-Olesen, A. \& Hansen, F. G. (1987). Overproduction of DnaA protein stimulates initiation of chromosome replication in Escherichia coli. Mol Gen Genet 206, 52-59.

Bramhill, D. \& Kornberg, A. (1988). A model for initiation at origins of DNA replication. Cell 54, 915-918.

Cole, S. T., Brosch, R., Parkhill, J. \& 39 other authors (1998). Deciphering the biology of Mycobacterium tuberculosis from the complete genome sequence. Nature 393, 537-544.

Foley-Thomas, E. M., Whipple, D. L., Bermudez, L. E. \& Barletta, R. G. (1995). Phage infection, transfection and transformation of Mycobacterium avium complex and Mycobacterium paratuberculosis. Microbiology 141, 1173-1181.

Fujita, M. Q., Yoshikawa, H. \& Ogasawara, N. (1990). Structure of the dnaA region of Micrococcus luteus: conservation and variations among eubacteria. Gene 93, 73-78.

Goto, Y., Taniguchi, H., Udou, T., Mizuguchi, Y. \& Tokunaga, T. (1991). Development of a new host vector system in mycobacteria. FEMS Microbiol Lett 83, 277-282.

Jacobs, W. R., Jr, Kalpana, G. V., Cirillo, J. D., Pascopella, L., Snapper, S. B., Udani, R., Jones, W., Barletta, R. G. \& Bloom, B. R. (1991). Genetic systems for mycobacteria. Methods Enzymol 204, 537-555.

Kornberg, A. \& Baker, T. (1991). DNA Replication. New York: W. H. Freeman. 
Laemmli, U. K. (1970). Cleavage of structural proteins during the assembly of the head of bacteriophage T4. Nature 227, 680-685.

Madiraju, M. V. V. S., Qin, M.-H. \& Rajagopalan, M. (1999). Development of simple and efficient protocol for isolation of plasmids from mycobacteria using zirconia beads. Lett Appl Microbiol (in press).

Moriya, S., Atlung, T., Hansen, F. G., Yoshikawa, H. \& Ogasawara N. (1992). Cloning of an autonomously replicating sequence (ars) from the Bacillus subtilis chromosome. Mol Microbiol 6 , 309-315.

Qin, M.-H., Madiraju, M. V. V. S., Zachariah, S. \& Rajagopalan, M. (1997). Characterization of the oriC region of Mycobacterium smegmatis. J Bacteriol 179, 6311-6317.

Qin, M.-H., Madiraju, M. V. V. S. \& Rajagopalan, M. (1999). Characterization of the functional replication origin of $\mathrm{Myco-}$ bacterium tuberculosis. Gene 233, 121-130.

Rajagopalan, M., Qin, M.-H., Steingrube, V. A., Nash, D. R., Wallace, R. J., Jr \& Madiraju, M. V. V. S. (1995a). Amplification and cloning of the Mycobacterium tuberculosis dnaA gene. Gene $163,75-79$.

Rajagopalan, M., Qin, M. H., Nash, D. R. \& Madiraju, M. V. V. S. (1995b). Mycobacterium smegmatis dnaA region and autonomous replication activity. J Bacteriol 177, 6527-6535.

Salazar, L., Fsihi, H., Rossi, E. D., Riccardi, G., Rios, C., Cole, S. T. \& Takiff, H. E. (1996). Organization of the origins of replication of the chromosomes of Mycobacterium smegmatis, Mycobacterium leprae and Mycobacterium tuberculosis and isolation of a functional origin from M. smegmatis. Mol Microbiol 20, 283-293.

Sambrook, J., Fritsch, E. F. \& Maniatis, T. (1989). Molecular Cloning: a Laboratory Manual, 2nd edn. Cold Spring Harbor, NY: Cold Spring Harbor Laboratory.

Skarstad, K. \& Boye, E. (1994). The initiator protein DnaA: evolution, properties and function. Biochim Biophys Acta 1217, 111-130.

Skovgaard, O. \& Hansen, F. G. (1987). Comparison of the $d n a A$ nucleotide sequences of Escherichia coli, Salmonella typhimurium and Serratia marcescens. J Bacteriol 169, 3976-3981.
Smith, D. W., Yee, T. W., Baird, C. \& Krishnapillai, V. (1991). Pseudomonad replication origins: a paradigm for bacterial origins? Mol Microbiol 5, 2581-2587.

Snapper, S. B., Melton, R. E., Mustafa, S., Kieser, T. \& Jacobs, W. R., Jr (1990). Isolation and characterization of efficient plasmid transformation mutants of Mycobacterium smegmatis. Mol Microbiol 4, 1911-1919.

Stover, C. K., de la Cruz, V. F., Fuerst, T. R. \& 11 other authors (1991). New use of BCG for recombinant vaccines. Nature 351, 456-460.

Studier, F. W., Rosenberg, A. H., Dunn, J. J. \& Dubendorff, J. W. (1990). Use of T7 polymerase to direct expression of cloned genes. Methods Enzymol 185, 60-89.

Wahl, S. M., Greenwell-Wild, T., Peng, G., Hale-Donze, H., Doherty, T. M., Mizel, D. \& Orenstein, J. M. (1998). Mycobacterium avium complex augments macrophage HIV-1 production and increases CCR5 expression. Proc Natl Acad Sci USA 95, 12574-12579.

Wards, B. J. \& Collins, D. M. (1996). Electroporation at elevated temperatures substantially improves transformation efficiency of slow-growing mycobacteria. FEMS Lett 145, 101-105.

Wheeler, P. R. \& Ratledge, C. (1994). Metabolism of Mycobacterium tuberculosis. In Tuberculosis: Pathogenesis, Protection and Control, pp. 353-358. Edited by B. R. Bloom. Washington, DC: American Society for Microbiology.

Yee, T. W. \& Smith, D. W. (1990). Pseudomonas chromosomal replication origins: A bacterial class distinct from Escherichia coli-type origins. Proc Natl Acad Sci USA 87, 1278-1282.

Zakrzewska-Czerwinksa, J. \& Schrempf, H. (1992). Characterization of an autonomously replicating region from the Streptomyces lividans chromosome. J Bacteriol 174, 2688-2693.

Zyskind, J. W. \& Smith, D. W. (1986). The bacterial origin of replication, oriC. Cell 46, 489-490.

Received 30 March 1999; revised 1 July 1999; accepted 5 July 1999 